\title{
Use of autologous bone marrow rich in stem cells as an osteoinducer in maxillary sinus elevation
}

\author{
Ibañez Juan Carlos $^{1 *}$, Juaneda Maria Agustina ${ }^{2}$, Ibañez Maria Constanza ${ }^{3}$ and Ibañez Santiago Luis ${ }^{4}$ \\ ${ }^{1}$ Dr in Dentistry, Director and Professor of the Career of Specialization in Oral Implantology, Faculty of Health Sciences of the Catholic University of Córdoba, Argentina \\ ${ }^{2}$ Dentist, Assistant Professor of the Career of Specialization in Oral Implantology, Faculty of Health Sciences of the Catholic University of Córdoba, Argentina \\ ${ }^{3}$ Dentist, Specialist in Oral Implantology, Assistant Professor of the Career of Specialization in Oral Implantology, Faculty of Health Sciences of the Catholic \\ University of Córdoba, Argentina \\ ${ }^{4}$ Traumatologist, Former Assistant Professor of the Chair of Traumatology, Cordoba Hospital, National University of Cordoba, Argentina
}

\begin{abstract}
Aim: To study the results that can be obtained when performing sinus lift technique by lateral opening with piezo surgery using as graft material a mixture of autologous bone marrow without any treatment and Bio-Oss (60:40) measuring the amount of bone tissue formed in the maxillary sinuses, the percentage of final vital bone obtained in the grafts and the success rate of the implants placed in those sinuses.

Materials and methods: 23 maxillary sinus lifting were performed in 13 patients (10 bilateral, 3 unilateral) using a mixture of bone marrow taken from distal femur with a xenograft (Bio-Oss) Lateral window sinus elevation technique using piezo surgery was used in all cases. 49 implants were placed and loaded. Graft volume, height and density were measure. Besides percentages of new bone, biomaterial remnant and connective tissue were also measure.

Results: Mean volume obtained was $1668 \mathrm{~mm} 3$, mean height was $10.9 \mathrm{~mm}$ and bone density was $648 \mathrm{HU}$. Percentage of new bone, biomaterial remnant and connective obtained were 37.08, 16.77 and 45.22 respectively. Finally, the percentage of success of the implants inserted in these grafted sinuses was $96 \%$

Conclusions: The use of a mixture of Bio-Oss with bone marrow obtained from the distal femur seems to be an efficient combination to obtain an adequate percentage of vital bone when sinus lifting is performed. Besides good results can be achieved when implants with microtextured surface are used in this type of sinus graft.
\end{abstract}

\section{Introduction}

The use of stem cells obtained from bone marrow as a therapeutic method is widespread [1] The bone marrow stem cells have been shown to facilitate the healing of different tissues including [2,3]. It contains hematopoietic stem cells and stromal cells that also contain mesenchymal stem cells (MSCs) that differentiate to various lineages [4].

Bone marrow with a high content of Stem Cells (SC) has been widely used in orthopedic procedures, for example, for the regeneration of cartilage at the distal end of the femur, at the medial end of the tibia or in the hips, as well as in other joints [5].

Hernigou et al. (2020) showed excellent results in the treatment of osteoarthritis of the knee when injected bone marrow into this joint [6], as well as in the hip [7] and non-unions in the tibia [8] or other long bones [9] using different concentrations of progenitor cells [10].

In addition to being used alone, stem cells can be combined with biomaterials to improve bone formation [11] Thus, for example, Coquelin L et al. (2012) used SC mixed with three different human bone allografts obtaining very good results [12].

In the field of dentistry there are different uses, ranging from trying to obtain dental tissues to obtain bone tissue [13]

Maxillary reconstruction has involved stem cells, especially mesenchymal cells [14], mixing them with osteoconductive materials or scaldfols [15]. Different works show an increase in the efficiency of these reconstructions using this combination showing better results than others osteoinducers [16-18].

One of the most complex situations to regenerate are very atrophic maxillary sinuses, where the receptor bed is practically a cortical therefore with little vascularity $[19,20]$.

Some studies show that the use of stem cells obtained from bone marrow mixed with osteoconductors has shown efficacy in improving the percentage of final vital bone in this type of procedure [21] as well as [22].

Rickert et al (2011) used stem cells from bone marrow obtained from posterior iliac crest [23]. They used an aspiration syringe previously sprayed with heparin and filled with $8 \mathrm{ml}$ of citric acid for obtaining the bone marrow, and them they isolated and concentrated the SC before mixing with a xenograft (Bio-Oss) for sinus graft. They compared this mixture against a mix of autologous bone and the same xenograft, obtaining better results when SC were used.

${ }^{*}$ Correspondence to: Juan Carlos Ibanez, Obispo Oro 414 Cordoba 5000 Argentina, Tel: +54 351 4680156; +54 9351 3842691; E-mail: dribanez@ ibaimplantes.com

Key words: bone marrow, dental implants, sinus lifting, stem cells

Received: May 14, 2020; Accepted: June 02, 2020; Published: June 05, 2020 
In a previous works carried out by our group, bone marrow obtained from the distal femur was used instead, but without using any anticoagulant; the marrow was used without any type of processing and was mixed with the same xenograft (Bio-Oss) obtaining also an increase in the final vital bone in the graft [21]. In this investigation, the extraction technique used was according to the work of Ibanez JR et al. (2006); In their research bone marrow from iliac crest and also from the distal femur were used [24].

The possibility of using the distal end of the femur as an alternative to the iliac crest was confirmed by Narbona, Vaquero and Fernández (2011) [25]. They compared the number of MSC that can be obtained from iliac crest, from tibiae and form the distal femur showing that although more cells can be obtain from iliac crest, the number of cells that be collected from the femur were also clinically adequate. In another paper the same authors confirm the efficacy of bone marrow from the distal femur when comparing the number and quality of the MSCs of this place with the iliac crest [26].

The aim of the present work is to study the results that can be obtained when performing sinus lift technique by lateral opening with piezo surgery using as graft material a mixture of autologous bone marrow without any treatment and Bio-Oss (60:40) measuring the amount of bone tissue formed in the maxillary sinuses, the percentage of final vital bone obtained in the grafts and the success rate of the implants placed in those sinuses.

\section{Material and methods}

Between June 2008 to August 2018, 23 maxillary sinus lifting were performed in 13 patients ( 10 bilateral, 3 unilateral) aged from 51 to 74 years old. After 9 months 49 implants were placed and 4 months later were loaded. Just before implant placement, volume and height obtained with the graft were measure in CBCT scans. Bone density was also measure in Hounsfield Units (HU) using Blue Sky Plan software. During implant surgery 11 biopsies were taken for histologic analysis. Besides resonance frequency analysis (RFA) of the implants was performed.

All the patients signed an informed consent form and the study was carried out in accordance with the International Ethical Guidelines for the Research and Biomedical Experimentation on Human Beings (Declaration of Helsinki 2008), ensuring the protection and confidentiality of patient data.

\section{Surgical protocol}

The surgeries were carried out during the regular courses of the Career of Specialization in Oral Implantology of the Catholic University of Cordoba, Argentine and in the author's private practice. Each patient was treated by two different operators, but exactly under the same protocol.

Lateral window sinus elevation technique [27] using piezo surgery [28] was used in all cases.

After opening the lateral window and controlled that the sinus mucosae was intact, an orthopedic surgeon anesthetized the lateral aspect of the lower end of the femur above the lateral epicondyle. Then with a $4 \mathrm{~mm}$ diameter trocar the cutaneous planes were crossed to pierce the thin bone immediately above the lateral epicondyle. Once the drilling was done, 5 to $10 \mathrm{~cm} 3$ of bone marrow was extracted with a $20 \mathrm{~cm} 3$ plastic syringe without any anticoagulant [29] (Figure 1).

The bone marrow was mix with anorganic bovine bone (ABB) (BioOss, Geistlich Pharma AG Bahnhofstrasse $40 \mathrm{CH}-6110$ Wolhusen)

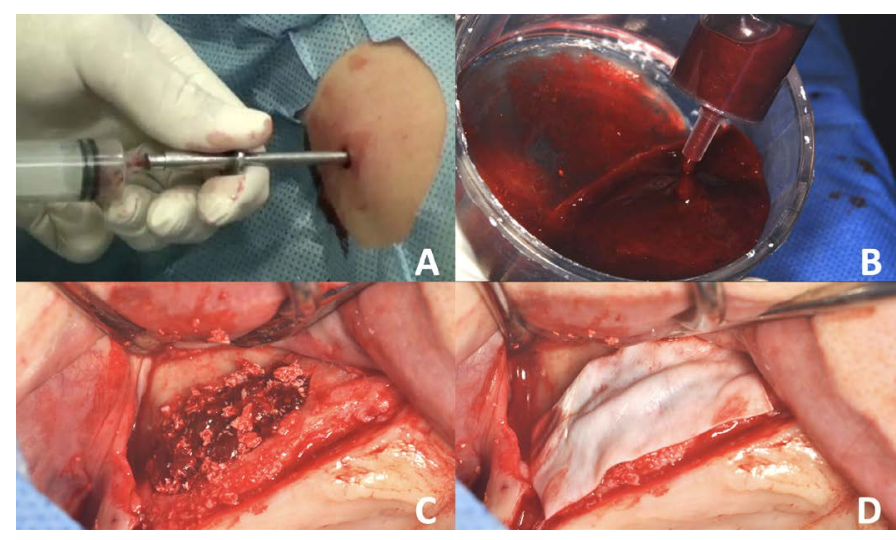

Figure 1. 1A - Extraction bone marrow from distal femur, 1B - Bone marrow, 1C Maxillary sinus grafted with bone marrow mixed with Bio-Oss, 1D - Collagen membrane (Bio-Gide) for lateral window closing

large particles (1-2um) in a 60: 40 proportion. The mix was used for grafting the sinus, and the lateral window was covered with a native collagen membrane (Bio-Gide, Geistlich Pharma AG Bahnhofstrasse $40 \mathrm{CH}$ - 6110 Wolhusen) Nylon suture was used to close the tissues.

After 9 months CBCT scans were taken in order to control the sinus grafting results and planning the implants placement surgery Figure 2.

Dual acid-etched surface tapered implants (Full Osseotite Tapered, Biomet 3i Palm Beach Gardens Fl USA) were inserted.

During implant placement surgery 11 biopsies were taken using a $3 \mathrm{~mm}$ external diameter trephine and immediately fixed in $10 \%$ formaldehyde. The sample was processed for histological and histomorphometric analysis with the aim of measure new bone (NB), xenograft (Bio-Oss) remnant (BR) and connective tissue (CT)

After implant placement RFA was performed with Osstell ISQ (Osstell, Stampgatan 14 SE 41101 Gothenburg Sweden) instrument to obtain implant stability quotient (ISQ)as described by Ibanez, Tahhan and Ibanez (2014) [30].

Four to six months later implants were loaded with the protheses according to treatment plan.

\section{Treatment of the samples for histology and histomorphometry}

Samples were decalcified, dehydrated, included in paraffin and mounted in a microtome with a disposable blade to obtain cuts from 3 to 10 microns thick. Them stained with hematoxylin and eosin and prepared for subsequent microscopic study.

For measurements, Image Pro-Plus v4.52 morphometry software was used on digitized microscopic images of the biopsies with $40 \mathrm{X}$ optical magnification. The digitalization was carried out using a Carl Zeiss optical microscope with camera incorporated. (Carl Zeiss -Axiocam Ic 5). If the panoramic magnification was insufficient to determine the type of tissue observed in any sector, higher magnifications were used.

The tissue to be measured was determined according to its histological characteristics, both by staining and by the shape and specific details. The specific procedure for measuring consisted in delimiting these areas with the tool provided by the software. For contrasting and well-defined paths, automatic edge detection was selected while the areas that were diffuse, faded or torn during the cutting process were delimited manually. Measurements corresponding to NB tissue were made first, then BR and finally TC was obtained by 
mathematical calculation. The data obtained were tabulated in an Excel spreadsheet for subsequent statistical analysis.

\section{Bone density in CBCT scans}

The CBCT DICOM images were processed with Blue Sky Plan 3 program (Blue Sky Bio, USA) in normal mode where the panoramic view was observed. The area of grafted bone was identified and differentiated from the native maxillary bone of each case and the measurement of the residual maxillary bone was taken at the point of least height. Then, in the sagittal section of the tomographic study that corresponds to the area of greatest volume of the grafted bone, the height of the grafting taken. In the same sagital view the center was identified and the first measurement of bone density was made, whose value is expressed in gray scale represented by software as Hounsfield Units (HU). Four measurements were also made from the first measurement: $2 \mathrm{~mm}$ coronal, $2 \mathrm{~mm}$ apical, $2 \mathrm{~mm}$ mesial and $2 \mathrm{~mm}$ distal. This allowed to take the average of the five values as a single value for each case. The bone density values obtained from the delimited areas were compared and the corresponding statistical analysis was performed.

\section{Graft volume in CBCT scans}

In the same scans and with the same software graft volume obtained was calculated. In the panoramic view the length of the graft was measure while the width and height were measure in a sagittal view. With these 3 values the volume was calculate for each sinus.

\section{Results}

All the sinus procedures had an uneventful heal. The mean volume obtained was $1668 \mathrm{~mm} 3$ ( $\min 652 \mathrm{~mm} \max 3105.80 \mathrm{~mm} 3$ ) The height achieved was between a maximum of $15,2 \mathrm{~mm}$ and a minimoon of 8 $\mathrm{mm}$ with a mean of $10,9 \mathrm{~mm}$. The mean of bone density was $648 \mathrm{HU}$ (min 368 HU max 998).

The distribution of new bone, xenograft (Bio-Oss) remnant and connective tissue obtained is shown in table 1 while an example of the histologic samples is shown in figure 3.

Forty-seven implants of the 49 -implant placed were successful. The mean ISQ obtained at implants placement was 63.3.

\section{Discussion}

All the maxillary sinus treated were successful and an adequate graft volume was obtained. The percentages of new bone, biomaterial remnant and connective tissue were $37.08,16.77$ and 45.22 respectively. Finally, the percentage of success of the implants inserted in these grafted sinuses was $96 \%$.
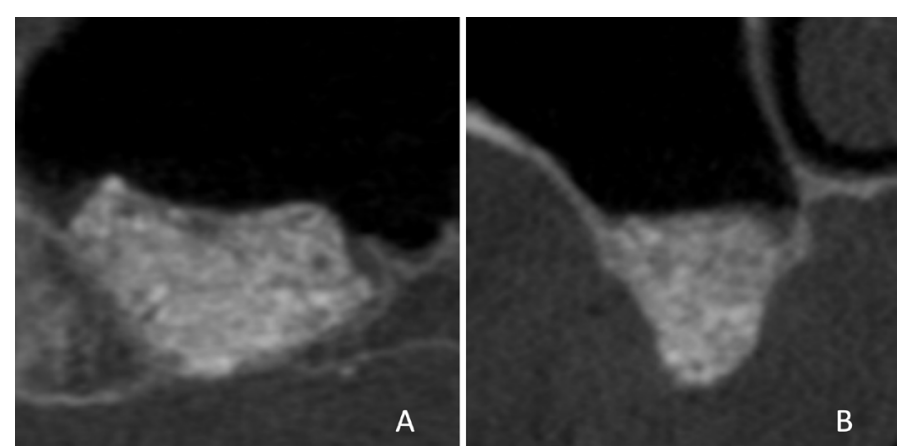

Figure 2. 2A - Grafted sinus after 9 months panoramic view, 2B - Grafted sinus after 9 months sagittal view

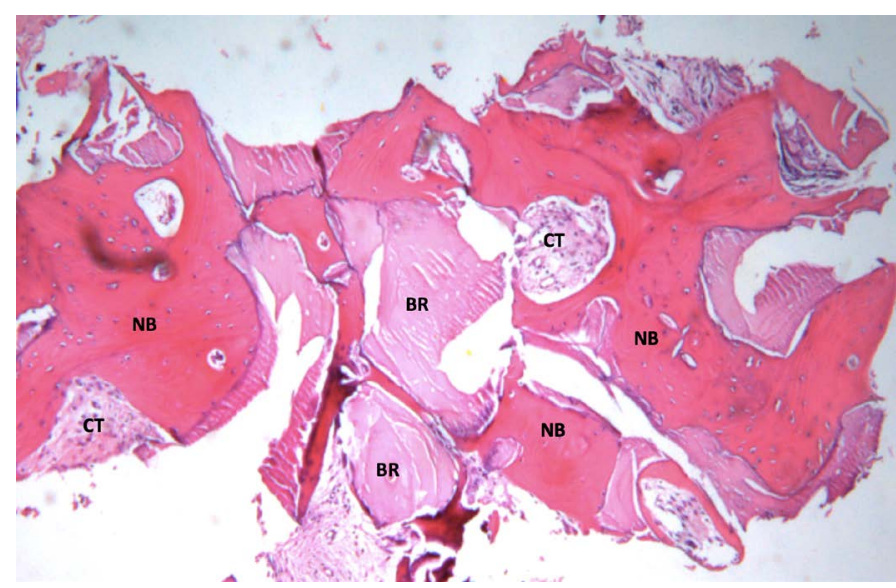

Figure 3. Histologic section showing areas of new bone (NB), Bio-Oss remnant (BR) and connective tissue (CT)

Table 1. Percentages of NB, BR and CT of each of the biopsies analyzed

\begin{tabular}{|c|c|c|c|}
\hline Sample & New Bone $\%$ & Bio-Oss Remnant\% & Conective Tissue $\%$ \\
\hline A & $52.10 \%$ & $13.00 \%$ & $34, .0 \%$ \\
\hline B & $25.50 \%$ & $33.80 \%$ & $40.70 \%$ \\
\hline C & $39.20 \%$ & $18.80 \%$ & $42.00 \%$ \\
\hline D & $25.40 \%$ & $12.00 \%$ & $62.60 \%$ \\
\hline E & $28.30 \%$ & $10.50 \%$ & $61.20 \%$ \\
\hline F & $40.20 \%$ & $8.80 \%$ & $51.00 \%$ \\
\hline G & $41.50 \%$ & $12.50 \%$ & $46.00 \%$ \\
\hline H & $47.10 \%$ & $11.60 \%$ & $41.30 \%$ \\
\hline I & $38.30 \%$ & $34.50 \%$ & $27.20 \%$ \\
\hline J & $38 \%$ & $11 \%$ & $51 \%$ \\
\hline K & $35.90 \%$ & $15 \%$ & $40.10 \%$ \\
\hline Mean & $37.08 \%$ & $16.77 \%$ & $45.22 \%$ \\
\hline
\end{tabular}

Hundred percent of the sinus heal normally. This result is similar or better than similar researches using bone marrow [22,29]. Rickert et al. (2011) treated bilateral sinus using Bio-Oss mixed with autologous bone in one side and Bio-Oss seeded with mononuclear stem cells harvested from the posterior iliac crest in the other side. Healing was uneventful in 11 of the 12 patients treated [23]. Similar results were achieved by Ferreira et al. 2009 [31], Jensen et al. (2007) [32] and others (Wallace et al. 2005, Barone et al. 2005) when treated maxillary cases using xenograft alone or with autogenous bone but without bone marrow $[33,34]$.

The volume for implants placement obtained at the sinus grafted was adequate. (mean $1668 \mathrm{~mm} 3$ ) This value is similar to obtained in other researches. Cabrera, Tahhan and Ibanez (2017) obtained a mean volume of $2.117 \mathrm{~mm} 3+/-630,0$ in a study using Bio-Oss alone as graft biomaterial [35] while Sbordone et al (2013) obtained a mean of $1230 \mathrm{~mm} 3$ [36].

Bone density of the grafts was measure in CBCT scans in HU obtaining a medium density of $648 \mathrm{HU}$ ( $\min 368 \mathrm{HU} \max 998$ ). This density corresponds with a type II-III bone according to Lekholm and Zarb (1985) classification [37] or a Type II considering Norton and Gamble (2001) classification [38].

In a similar research but with other materials Sbordone et al (2013) showed a mean density of $781 \mathrm{HU}$ [36]. Seiler, Ibanez and Ibanez (2019) using Bio-Oss measured 13 CBCT scans founding a mean of $625 \mathrm{HU}[39]$.

The percentage of new vital bone obtained in the biopsies in the present research was high $(37.08 \%)$ in relation to other studies, and 
the same can be said about BR and CT. Rickert et al (2011) obtained a mean of $13,9 \%$ of new bone but the performed the biopsies earlier (14.8 weeks, range $13.3-15.8$ weeks) The mean BR was $31.3 \%$ and the soft tissues were $52.5 \%$ These differences could be explain by the shortest period of healing used [23]. Hirata, Ueno and Moy (2017) found more percentage of NB in sinus lifting procedures using another osteoinductive material, rhBMP-2 at concentration $1.5 \mathrm{mg} / \mathrm{mL}$ with an absorbable collagen sponge (ACS). They grafted 10 sinuses obtaining $44,2 \%$ of new bone [40]. Shirmohammadi A et al. (2014) performed sinus elevation using Bio-Oss mixed with $20 \%$ of autogenous bone obtaining $25,3 \%$ at 5 months biopsies, lower values than the present study [41]. One the other hand, when Bio-Oss alone was used the results in terms of vital bone were variable. Norton, Odell and Cook (2003) found 25,6\% of new bone [42] and Cordaro et al. (2008) obtained 19.6 $\%$ [43] Besides Ferreira C et al. (2009) found 39\% of NB [44].

In the present study 49 dual-acid etched (DAE) implants were inserted in the grafted maxillary sinus. Only 2 implants were lost. (96\% success) Ibanez, Tahhan and Zamar (2003) and Ibanez et al. (2005) $[45,46]$ found similar success rate in two researches using the same type of implants but in different situations different than sinus grafting. In another study that did included implants placed in sinus lifting procedures, they (Ibanez et al. 2020) obtained 95,59\% in a 1 to 15 years follow-up [47]. Sbordone et al. (2009) in a research comparing sinus lifting implant success vs success in native bone areas a significative difference between both groups $(85 \% v s 95,8)$ but the graft material used in this study was particulate chin bone [48]. In the other hand Ferreira et al. (2009) using Bio-Oss alone for the sinus graft obtained a $98 \%$ of success of the implants [44].

Just after implant placement, RFA was taken using Osstell ISQ device in order to measure implant stability in this type of graft procedure [30]. The mean ISQ value obtained was 63.3. This result is adequate for the type of bone achieved in the present study. Gallardo, Ibanez and Ibanez (2016) obtained a mean value of 70.5 using the same implants $(\mathrm{n}=279)$ but in native bone [49]. Hsu A et al (2016) compared the ISQ of 45 implants placed with different anchorages and obtained a mean ISQ of 75.9 when tested indirect sinus elevation implants [50]. By his side Park et al (2019) using tapered implants in lateral window sinus grafted obtained a mean ISQ of 68.40 for their implants, a similar result than our study [51].

\section{Conclusions}

Due to the results of this preliminary report, the use of a mixture of Bio-Oss with bone marrow obtained from the distal femur seems to be an efficient combination to obtain an adequate percentage of vital bone when sinus lifting is performed. Besides good results can be achieved when implants with microtextured surface are used in this type of sinus graft.

\section{Authorship and Contributorship}

Dr Juan Carlos Ibanez and conceived the ideas, performed most of the sinus surgeries and implant insertion, analysed the data and led the writing; Maria A Juaneda and Maria C Ibanez collaborate in the surgeries, collected and analysed the data and collaborate with the writing. Dr Santiago Ibanez conceived the ideas, performed the bone marrow extraction and collaborate with the writing.

The authors did not received any founds for the development and realization of the research.

The authors does not have any conflict of interest in relation to the present research.

\section{References}

1. Hasty KA, Cho H (2016) Stem Cell Considerations for the Clinician. Phys Med Rehabil Clin N Am 27(4):855-870.

2. Bianco P, Riminucci M, Gronthos S, Gehron Robey P (2001) Bone Marrow Stromal Stem Cells. Nature, Biology, and Potential Applications Stem Cells 19:180-192.

3. Polymeri A, Giannobile WV, Kaigler D (2016) Bone Marrow Stromal Cells in Tissue Engineering and Regenerative Medicine. Horm Metab Res 48(11):700-713.

4. Benayahu D, Akavia UD, Shur I (2007) Differentiation of bone marrow stroma- derived mesenchymal cells. Curr Med Chem 14(2):173-9.

5. Hernigou P, Beaujean F (1997) Bone marrow in patients with pseudarthrosis. A study of progenitor cell by in vitro cloning. Rev Chir Orthop Reparatrice Appar Mot 83(1):33-40.

6. Hernigou P, Delambre J, Quiennec S, Poignard A (2020) Human bone marrow mesenchymal stem cell injection in subchondral lesions of knee osteoarthritis: a prospective randomized study versus contralateral arthroplasty at a mean fifteen years follow-up. Int Orthop Apr 23.

7. Hernigou P, Poignard A, Zilber S, Rouard H (2009) Cell therapy of hip osteonecrosis with autologous bone marrow grafting. Indian J Orthop 43(1):40-5.

8. Hernigou P, Mathieu G, Poignard A, Manicom O, Beaujean F, Rouard H.J (2006) Percutaneous autologous bone-marrow grafting for nonunions. Surgical technique. Bone Joint Surg Am 88:322-7.

9. Gómez-Barrena E, Padilla-Eguiluz N, Rosset P, Gebhard F, Hernigou P, et al. (2020) Early efficacy evaluation of mesenchymal stroma cells (MSC) combined to biomaterials to treat long bone non-unions. Injury 26: S0020-1383(20)30144-3.

10. Hernigou P, Poignard A, Beaujean F, Rouard H.J (2005) Percutaneous autologous bone-marrow grafting for nonunions. Influence of the number and concentration of progenitor cells. Bone Joint Surg Am 87(7):1430-7.

11. Léotot J, Lebouvier A, Hernigou P, Bierling P, Rouard H, et al. (2015) Bone-Forming Capacity and Biodistribution of Bone Marrow-Derived Stromal Cells Directly Loaded Into Scaffolds: A Novel and Easy Approach for Clinical Application of Bone Regeneration. Cell Transplant 24(10):1945-55.

12. Coquelin L, Fialaire-Legendre A, Roux S, Poignard A, Bierling P, et al. (2012) In vivo and in vitro comparison of three different allografts vitalized with human mesenchymal stromal cells. Tissue Eng Part A 18(17-18):1921-31.

13. Tatullo M (2018) About stem cell research in dentistry: many doubts and too many pitfalls still affect the regenerative dentistry. Int J Med Sci 20;15(14):1616-1618.

14. Dominici M, Le Blanc K, Mueller I, Slaper-Cortenbach I, Marini F, et al. (2006) Minimal criteria for defining multipotent mesenchymal stromal cells. The International Society for Cellular Therapy position statement. Cytotherapy 8(4):315-7.

15. Mahesh H, Mankani SA, Kuznetsov RM, Wolfe GW, Marshall P, et al. (2006) In Vivo Bone Formation by Human Bone Marrow Stromal Cells: Reconstruction of the Mouse Calvarium and Mandible. Stem Cells 24(9):2140 -2149.

16. Jafarian M, Eslaminejad MB, Khojasteh A, Mashhadi Abbas F, Dehghan MM, et a (2008) Marrow-derived mesenchymal stem cells-directed bone regeneration in the dog mandible: a comparison between biphasic calcium phosphate and natural bone mineral. Oral Surg Oral Med Oral Pathol Oral Radiol Endod 105(5): e14-24.

17. Khojasteh A, Eslaminejad MR, Nazarian H (2008) Mesenchymal stem cells enhance bone regeneration in rat calvarial critical size defects more than platelete-rich plasma. Oral Surg Oral Med Oral Pathol Oral Radiol Endod 106(3):356-62.

18. Smiler D, Soltan M, Lee JW (2007) A histomorphogenic analysis of bone grafts augmented with adult stem cells. Implant Dent 16(1):42-53.

19. Esposito M, Felice P, Worthington HV (2014) Interventions for replacing missing teeth: augmentation procedures of the maxillary sinus. Cochrane Database Syst Rev 13;(5):CD008397.

20. Tilaveridis I, Lazaridou M, Zouloumis L, Dimitrakopoulos I, Tilaveridis V, et al. (2018) The use of mineralized bone allograft as a single grafting material in maxillary sinus lifting with severely atrophied alveolar ridge $(1-3 \mathrm{~mm})$ and immediately inserted dental implants. A 3-up to 8 years retrospective study. Oral Maxillofac Surg 22(3):267-273.

21. Ibanez JC, Juaneda MA, Ibanez MC, Ibanez MI (2012) Bio-Oss and stem cells from bone marrow obtained from the distal femur for sinus. Clin Oral Implants Res 23:228-261.

22. Chen XL, Li ZL, Zhang WB, Ye ZC, Ke SN (2007) Experimental study of maxillary sinus lifting with tissue engineered bone. Zhonghua Kou Qiang Yi Xue Za Zhi 42(10):610-3. 
23. Rickert D, Sauerbier S, Nagursky H, Menne D, Vissink A, et al. (2011) Maxillary sinus floor elevation with bovine bone mineral combined with either autogenous bone or autogenous stem cells: a prospective randomized clinical trial. Clin Oral Impl Res 22:251-258.

24. Ibanez JR, Monge AG, Ibanez S, Monge P, Ibanez AH. (2006) Treatment of Bone Necrosis with an Autologous Bone Marrow Graft. Results at 10 years [Poster]. $6^{\text {th }}$ International Cartilage Repair Society Symposium, San Diego, California, 2006.

25. Narbona FJ, Vaquero Martín J, Fernández Santos ME (2012) Mononuclear cell concentration as predictive tool of mesenchimal stem cells on bone marrow aspiration. A comparative study between iliac crest, distal femur metaphysis and proximal tibial metaphysis. Trauma Fund MAPFRE 23(2):91-96.

26. Narbona-Carceles J, Vaquero J, Suárez-Sancho S, Forriol F, Fernández-Santos ME (2014) Bone marrow mesenchymal stem cell aspirates from alternative sources: Is the knee as good as the iliac crest? Injury 45(4):42-47.

27. Boyne PJ, James RA (1980) Grafting of the maxillary sinus floor with autogenous marrow and bone. J Oral Surg 38(8):613-16.

28. Vercellotti T, De Paoli S, Nevins M (2001) The piezoelectric bony window osteotomy and sinus membrane elevation: introduction of a new technique for simplification of the sinus augmentation procedure. Int J Periodontics Restorative Dent 21(6):561-7

29. Ibanez MC, Ibanez MI, Ibanez JC. 2011. Bio-Oss y células madres de medula ósea obtenidas del extremo distal de fémur para relleno de seno maxilar. Libro de Congresos de la Asociación Prostodóntica Argentina 4to IMPROGER Cordoba Argentina.

30. Ibáñez MC, Tahhan M, Ibáñez JC (2014) Influencia de la orientación del sensor Osstell ISQ en los valores del coeficiente de estabilidad de los implantes Rev Asoc Odontol Argent 102:166-171.

31. Ferreira CE, Novaes AB, Haraszthy VI, Bittencourt M, Martinelli CB, Luczyszyn SM (2009) A clinical study of 406 sinus augmentations with $100 \%$ anorganic bovine bone. J Periodontol 80(12):1920-1927.

32. Jensen T, Schou S, Stavropoulos A, Terheyden H, Holmstrup P (2012) Maxillary sinus floor augmentation with Bio-Oss or Bio-Oss mixed with autogenous bone as graft: a systematic review. Clin Oral Implants Res 23(3):263-73.

33. Wallace SS, Froum SJ, Cho SC, Elian N, Monteiro D, et al. (2005) Sinus augmentation utilizing anorganic bovine bone (Bio-Oss) with absorbable and nonabsorbable membranes placed over the lateral window: histomorphometric and clinical analyses. Int J Periodontics Restorative Dent 25(6):551-9.

34. Barone A, Crespi R, Aldini NN, Fini M, Giardino R, Covani U (2005) Maxillary sinus augmentation: histologic and histomorphometric analysis. Int J Oral Maxillofac Implants 20(4):519-25.

35. Cabrera D, Tahhan M, Ibanez JC (2017) Evaluación de niveles de ganancia ósea en injertos de seno maxilar con apertura lateral. Estudio tomográfico. [online]. Available at: Researchgate.net [accessed November 2017].

36. Sbordone C, Toti P, Guidetti F, Califano L, Bufo P, et al. (2013) Volume changes of autogenous bone after sinus lifting and grafting procedures: A 6-year computerized tomographic follow-up. Journal of Cranio-Maxillofacial Surgery 41(3):235-241.

37. Lekholm U, Zarb GA (1985) Patient selection and preparation. Tissue integrated prostheses; osseointegration in clinical dentistry. Edited by Branemark PI, Zarb GA, Albrektsson T. Quintessence Publishing Company 199-209.
38. Norton MR, Gamble C (2001) Bone classification: an objective scale of bone density using the computerized tomography scan. Clin Oral Impl Res 12:79-84.

39. Seiler E, Ibanez MC, Ibanez JC (2019) Bone density evaluation measured at ConeBeam Computed Tomography by means of Hounsfield Units in Maxillary Sinus Floor Augmentation [online]. Available at: Researchgate.net [accessed July 2019].

40. Hirata A, Ueno T, Moy PK (2017) Newly Formed Bone Induced by Recombinant Human Bone Morphogenetic Protein-2: A Histological Observation. Implant Dent 26(2):173-177.

41. Shirmohammadi A, Roshangar L, Chitsazi MT, Pourabbas R, Faramarzie M, et al (2014) Comparative Study on the Efficacy of Anorganic Bovine Bone (Bio-Oss) and Nanocrystalline Hydroxyapatite (Ostim) in Maxillary Sinus Floor Augmentation. Int Sch Res Notices 29;967091.

42. Norton M, Odell E, Thompson I, Cook R (2003) Efficacy of bovine bone mineral for alveolar augmentation: a human histologic study. Clinical Oral Implants Research 14(6): 775-783.

43. Cordaro L, Bosshardt DD, Palattella P, Rao W, Serino G, et al. (2008) Maxillary sinus grafting with Bio-Oss or Straumann Bone Ceramic: histomorphometric results from a randomized controlled multicenter clinical trial. Clin Oral Implants Res 19(8):796-803.

44. Ferreira CE, Novaes AB, Haraszthy VI, Bittencourt M, Martinelli CB, et al. (2009) A clinical study of 406 sinus augmentations with $100 \%$ anorganic bovine bone. $J$ Periodontol 80(12):1920-7.

45. Ibañez JC, Tahhan MJ, Zamar JA (2003) Performance of double acid-etched surface external hex titanium implants in relation to one- and two-stage surgical procedures. $J$ Periodontol 74(11):1575-81.

46. Ibanez JC, Tahhan MJ, Zamar JA, Menendez AB, Juaneda MA, et al. (2005) Immediate occlusal loading of double acid-etched surface titanium implants in 41 consecutive full-arch cases in the mandible and maxilla: 6- to 74-month results. $J$ Periodontol 76(11):1972-81.

47. Ibañez JC, Fuks D, Juaneda MA, Ibanez MI, Ibanez MC, et al. (2020) Long-Term Evaluation of Dental Implants in the Elderly Population. Scientific Archives of Dental Sciences 32(2020):01-09.

48. Sbordone L, Toti P, Menchini-Fabris G, Sbordone C, Guidetti F (2009) Implant succes in sinus-lifted maxillae and native bone: a 3-year clinical and computerized tomographic follow-up. Int J Oral Maxillofac Implants 24(2):316-24.

49. Gallardo S, Ibañez MC. Ibañez JC (2016) Correlation between ISQ and Insertion Torque values using double acid-etched implants. J Osseointegr 8(3):29-36.

50. Hsu A, Seong WJ, Wolff R, Zhang L, Hodges J, et al. (2016) Comparison of Initial Implant Stability of Implants Placed Using Bicortical Fixation, Indirect Sinus Elevation, and Unicortical Fixation. Int J Oral Maxillofac Implants 31(2):459-68

51. Park YH, Jung UW, Kim CS, Choi SH, Cho KS, et al. (2019) Resonance Frequency Analysis of Tapered Implants Placed at Maxillary Posterior Sites After Lateral Sinus Augmentation: A 1.5-year Follow-Up Prospective Study. Implant Dent 28(1):62-67.

Copyright: (C2020 Ibanez JC. This is an open-access article distributed under the terms of the Creative Commons Attribution License, which permits unrestricted use, distribution, and reproduction in any medium, provided the original author and source are credited. 